\title{
RELIABILITY MEASURES OF A 1-OUT-OF-2 SYSTEM WITH STANDBY AND DELAYED SERVICE
}

\author{
POOJA JAIN, D. PAWAR \& S.C. MALIK \\ Dronacharya College of Engineering, Gurgaon, India \\ Department of Statistics, Amity Institute of Applied Sciences, Amity University, Noida, India \\ Department of Statistics, M. D. University, Rohtak, India
}

\begin{abstract}
In this paper, reliability measures of a stochastic model developed for a 1-out-of-2 system with single standby are obtained by considering delayed service. The system consists of three identical units, two are initially operative and one is in cold standby. The system remains operative if any one of the units operates and system fails at the failure of the entire units. Each unit is in either operative or complete failure mode. Single server carries out the repair of failed unit with delay while reaching the system. However, server visits the system immediately if all the three units fail. Switch devices are faultless and repaired unit works similar to new one. Random variables of failure time, repair time and arrival time (or delay time) of the server are statistically independent. Semi-Markov process and regenerative point technique are used to evaluate mean time to system failure (MTSF), steady state availability, and busy period of the server and profit of the system. The trend of various reliability measures for a particular case are shown graphically.
\end{abstract}

KEYWORDS: 1-Out-Of-2 System, Identical Units, Reliability, Evaluation and Delayed Service

Received: Jun 08, 2020; Accepted: Jun 28, 2020; Published: Sep 14, 2020; Paper Id.: IJMPERDJUN20201212

\section{INTRODUCTION}

Redundancy and service discipline play an important role in increasing the availability and thus profit of the system. Keeping this fact in mind scholars including Murari and Goel (1984) compared two-unit cold standby system with three types of repair facilities, Singh (1989) evaluated the profit of a two-unit cold standby system with random appearance and disappearance time of the service facility, Malik and Bhardwaj(2007) analyzed profit and reliability of 2-out-of-3 redundant system with general distribution of repair and waiting time. Malik and Gitanjali (2012) discussed aparallel system with maximum repair time and single server who appears and disappears randomly. Chopra and Ram (2017) analyzed a two non-identical unit parallel system stochastically with waiting time. All these researchers' analyzed parallel systems with waiting time of the server or random appearance and disappearance of the server.

It is a known fact that down time of the system keeps on increasing with the increase of waiting time of the server and thus due to delay in service facility. Therefore, to increase the availability of the system there must be a clausein administration design that server will visit the system immediately at its complete failure. This will decrease the down time of the system and hence optimize the profit. Further, a two-unit parallel system can be made more reliable by providing one additional unit as cold standby. For instance, availability of petrol pumps having two machines working simultaneously all the while might be expanded by providing a third machine as a backup. In such cases one of the working units fails and backup unit will 
replace the failed one. Also, system will be working continuously until all the machines quit working. Keeping the above facts in mind we developed a comprehensive mathematical model with following assumptions:

- The system comprises of three indistinguishable units - two are in use and one is in cold standby.

- Each unit has two modes-working or failed.

- The system remains operative till the time at least one of the units is operative.

- There is a single server who takes time (delay time) to visit the failed unitand visits the system immediately if all the units fail.

- The failure time of the units are exponentially distributed while the distributions of repair rates are arbitrary.

- All the random variables are statistically independent.

- Semi-Markov process and regenerative point technique is used for the evaluation of various reliability measures.

- The switch devices are faultless and repaired unit works similar to new.

- For particular case, various reliability measures are shown graphically.

\subsection{Notations}

- $\quad$ 0: Unit is in operative mode.

- $\lambda$ : Constant failure rate of a single unit.

- $\mathbf{g}(\mathbf{t}) / \mathbf{G}(\mathbf{t}):$ Probability density function (pdf)/cumulative distribution function (cdf)of repair time of the unit.

- $\mathbf{w}(\mathbf{t}) / \mathbf{W}(\mathbf{t}): \mathrm{pdf} / \mathrm{cdf}$ of waiting time of the server.

- fur/FUR: Unit is completely failed and under repair/under continuous repair.

- fwr/FWR: Unit is completely failed and waiting for repair/ continuously waiting for repair.

- $\quad \mathbf{q}_{\mathrm{ij}}(\mathrm{t}) / \mathbf{Q}_{\mathrm{ij}}(\mathbf{t}): \mathrm{pdf} / \mathrm{cdf}$ of first passage time from regenerative state $\mathrm{i}$ to a regenerative state $\mathrm{j}$ or to a failed state $\mathrm{j}$ without visiting any other regenerative state in $(0, t]$.

- $\quad \mathbf{m}_{\mathrm{ij}}$ : The unconditional mean time taken by the system to transit from any regenerative state $\mathrm{S}_{\mathrm{i}}$ when it (time) is counted from epoch of entrance in to the stateS ${ }_{j}$. Mathematically, it can be written $\operatorname{asm}_{i j}=\int_{0}^{\infty} t d\left[Q_{i j}(t)\right]=-q_{i j}^{*^{\prime}}(0)$.

- $\mu_{\mathrm{i}}$ : Mean sojourn time in state $\mathrm{S}_{\mathrm{i}}$ which is given by $\mu_{\mathrm{i}}=\mathrm{E}(\mathrm{T})=\int \mathrm{P}\left(\mathrm{T}_{\mathrm{i}}>t\right) \mathrm{dt}=\sum_{\mathrm{j}} \mathrm{m}_{\mathrm{ij}}$, where $\mathrm{T}$ denotes the time to system failure.

- $\quad \mathbf{M}_{\mathbf{i}}(\mathbf{t})$ : Probability that the system is initially up in the regenerative state $S_{\mathrm{i}}$ at time ' $\mathrm{t}$ ' without passing through any other regenerative state.

- $\quad \mathbf{W}_{\mathbf{i}}(\mathbf{t})$ : Probability that the server is busy in the state $S_{\mathrm{i}}$ upto time ' $\mathrm{t}$ ', without making any transition to any other regenerative state or returning to the same via one or more non-regenerative states.

- $\quad$ (B) @ / ': Symbol of Stieltjes Convolution / Laplace Convolution/ derivative of the function. 
- $\quad * * / *$ : Symbol of Laplace Stieltjes Transform (LST)/ Laplace Transform (LT).

The transition states for the model are regenerative. The possible transition between states along with transition rate for the model is shown in Figure 1.

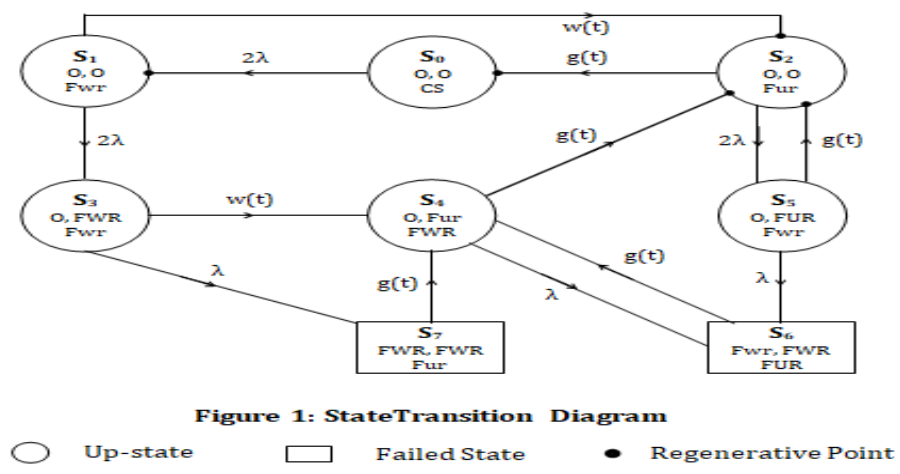

Figure 1: State Transition Diagram.

\subsection{Transition probabilities and mean Sojourn Times}

Simple probabilistic considerations yield the following expressions for the non-zero elements

$$
\begin{aligned}
& \mathrm{p}_{\mathrm{ij}}(\mathrm{t})=\mathrm{Q}_{\mathrm{ij}}(\infty)=\int \mathrm{q}_{\mathrm{ij}}(\mathrm{t}) \mathrm{dt} \\
& \mathrm{p}_{01}=\mathrm{p}_{64}=\mathrm{p}_{74}=1, \quad \mathrm{p}_{12}=\mathrm{w}^{*}(2 \lambda), \mathrm{p}_{13}=1-\mathrm{w}^{*}(2 \lambda), \mathrm{p}_{20}=\mathrm{g}^{*}(2 \lambda), \mathrm{p}_{25}=1-\mathrm{g}^{*}(2 \lambda), \\
& \mathrm{p}_{34}=\mathrm{w}^{*}(\lambda), \mathrm{p}_{37}=1-\mathrm{w}^{*}(\lambda), \mathrm{p}_{42}=\mathrm{p}_{52}=\mathrm{g}^{*}(\lambda), \mathrm{p}_{46}=\mathrm{p}_{56}=1-\mathrm{g}^{*}(\lambda)
\end{aligned}
$$

It can be verified that

$$
\mathrm{p}_{01}=\mathrm{p}_{12}+\mathrm{p}_{13}=\mathrm{p}_{20}+\mathrm{p}_{25}=\mathrm{p}_{34}+\mathrm{p}_{37}=\mathrm{p}_{42}+\mathrm{p}_{46}=\mathrm{p}_{52}+\mathrm{p}_{56}=\mathrm{p}_{64}=\mathrm{p}_{74}=1
$$

The mean sojourn times $\mu_{\mathrm{i}}$ in the state $S_{\mathrm{i}}$ are

$$
\mu_{0}=\int_{0}^{\infty} \mathrm{P}(\mathrm{T}>\mathrm{t}) \mathrm{dt}=\frac{1}{2 \lambda^{\prime}}, \mu_{1}=\frac{1}{2 \lambda}\left\{1-\mathrm{w}^{*}(2 \lambda)\right\}, \quad \mu_{2}=\frac{1}{2 \lambda}\left\{1-\mathrm{g}^{*}(2 \lambda)\right\}
$$

The unconditional mean time taken by the system to transit for any regenerative state $S_{j}$ when it (time) is counted from the epoch of entrance into the state $S_{i}$ is mathematically,states as

$$
\begin{aligned}
& \int_{0}^{\infty} \mathrm{tq}_{\mathrm{ij}}(\mathrm{t}) \mathrm{dt}=-\mathrm{q}_{\mathrm{ij}}^{* \prime}(0) \\
& \mu_{1}=m_{12}+\mu_{13}, \mu_{2}=m_{20}+\mu_{25}, \mu_{1}^{\prime}=m_{12}+\mu_{12 \cdot 34}+m_{17 \cdot 3}+\mu_{16 \cdot 34}, \mu_{2}^{\prime}=m_{20}+\mu_{22 \cdot 5}+m_{26 \cdot 5} \text {, }
\end{aligned}
$$

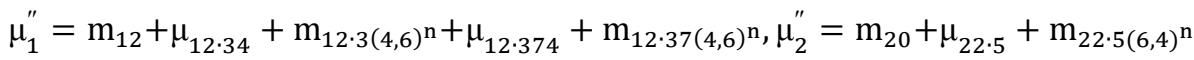

\subsection{Reliability and Mean Time to System Failure (MTSF)}

Let $\emptyset_{\mathrm{i}}(\mathrm{t})$ be the cdf of first passage time from the regenerative state $\mathrm{i}$ to a failedstate. Regarding the failed state as absorbing state, we have the following recursive relation for $\emptyset_{\mathrm{i}}(\mathrm{t})$ :

$$
\begin{aligned}
& \phi_{0}(\mathrm{t})=\mathrm{Q}_{01}(\mathrm{t}) \AA \phi_{1}(\mathrm{t}) \\
& \phi_{1}(\mathrm{t})=\left[\mathrm{Q}_{12}(\mathrm{t})+\mathrm{Q}_{12 \cdot 34}(\mathrm{t})\right] \circledR \phi_{2}(\mathrm{t})+\mathrm{Q}_{17 \cdot 3}(\mathrm{t})+\mathrm{Q}_{16 \cdot 34}(\mathrm{t})
\end{aligned}
$$




$$
\phi_{2}(\mathrm{t})=\mathrm{Q}_{20}(\mathrm{t}) \AA_{0}(\mathrm{t})+\mathrm{Q}_{26 \cdot 5}(\mathrm{t})+\mathrm{Q}_{22 \cdot 5}(\mathrm{t}){ }^{\circledR} \phi_{2}(\mathrm{t})
$$

Taking LST of above relation (5) and solving for $\phi_{0}^{* *}(\mathrm{~s})$, we have

$$
\mathrm{R}^{*}(\mathrm{~s})=\frac{1-\emptyset_{0}^{*}(\mathrm{~s})}{\mathrm{s}}
$$

The reliability of the system model can be obtained by taking inverse LT of (6).

The mean time to system failure (MTSF) is given bylim ${ }_{s \rightarrow \infty} R^{*}(s)$. Thus,

$$
\operatorname{MTSF}=\frac{\mathrm{N}_{0}}{\mathrm{D}_{0}}=\frac{\left(1-\mathrm{p}_{22 \cdot 5}\right)\left(\mu_{0}+\mu_{1}^{\prime}\right)+\mu_{2}^{\prime}\left(\mathrm{p}_{12}+\mathrm{p}_{12 \cdot 34}\right)}{1-\mathrm{p}_{22 \cdot 5}-\mathrm{p}_{20}\left(\mathrm{p}_{12}+\mathrm{p}_{12 \cdot 34}\right)}
$$

\subsection{Steady State Availability}

Let $A_{i}(t)$ be the probability that the system is in upstate at instant't' given that the system entered regenerative state $i$ at $t=0$. The recursive relations for $A_{i}(t)$ are given as:

$$
\begin{aligned}
& A_{0}(t)=M_{0}(t)+q_{01}(t) \odot A_{1}(t) \\
& A_{1}(t)=M_{1}(t)+\left[q_{12}(t)+q_{12 \cdot 34}(t)+q_{12 \cdot 37(4,6)^{n}}(t)+q_{12 \cdot 374}(t)+q_{12 \cdot 3(4,6)^{n}}(t)\right] \odot A_{2}(t) \\
& A_{2}(t)=M_{2}(t)+q_{20}(t) \oplus A_{0}(t)+\left[q_{22 \cdot 5}(t)+q_{22 \cdot 5(6,4)^{n}}(t)\right] \oplus A_{2}(t) \\
& \text { where } M_{0}(t)=e^{-2 \lambda t}, M_{1}(t)=e^{-2 \lambda t} \bar{W}(t), M_{2}(t)=e^{-2 \lambda t} \bar{G}(t)
\end{aligned}
$$

Taking LT of (7) and solving for $A_{0}^{*}(s)$, the steady state availability is given by

$$
\mathrm{A}(\infty)=\lim _{\mathrm{s} \rightarrow 0} \mathrm{~s} \mathrm{~A}_{0}^{*}(\mathrm{~s})=\frac{\mathrm{N}_{1}}{\mathrm{D}_{1}}=\frac{\mu_{0} \mathrm{p}_{20}+\mu_{1} \mathrm{p}_{20}+\mu_{2}}{\mu_{0} \mathrm{p}_{20}+\mu_{1}^{\prime \prime} \mathrm{p}_{20}+\mu_{2}^{\prime \prime}}
$$

\subsection{Busy Period of the Server}

Let $B_{i}^{R}(t)$ be the probability that the server is busy in repairing the unit at an instant ' $t$ ' given that the system entered regenerative state $i$ at $t=0$. The recursive relations for $B_{i}^{R}(t)$ are:

$$
\begin{aligned}
& \mathrm{B}_{0}(\mathrm{t})=\mathrm{q}_{01}(\mathrm{t}) \odot \mathrm{B}_{1}(\mathrm{t}) \\
& B_{1}(t)=M_{1}(t)+\left[q_{12}(t)+q_{12 \cdot 34}(t)+q_{12 \cdot 37(4,6)^{n}}(t)+q_{12 \cdot 374}(t)+q_{12 \cdot 3(4,6)^{n}}(t)\right] \odot B_{2}(t) \\
& B_{2}(t)=W_{2}(t)+q_{20}(t) \oplus B_{0}(t)+\left[q_{22 \cdot 5}(t)+q_{22 \cdot 5(6,4)^{n}}(t)\right] \oplus B_{2}(t)
\end{aligned}
$$

Where

$$
\mathrm{W}_{2}(\mathrm{t})=\mathrm{e}^{-2 \lambda \mathrm{t}} \overline{\mathrm{G}}(\mathrm{t})+\left(2 \lambda \mathrm{e}^{-2 \lambda t} \odot 1\right) \overline{\mathrm{G}}(\mathrm{t})+\left(2 \lambda \mathrm{e}^{-2 \lambda t} \odot \lambda \mathrm{e}^{-\lambda \mathrm{t}} \odot\left(\mathrm{g}(\mathrm{t}) \odot \lambda \mathrm{e}^{-\lambda t}\right)^{\mathrm{n}} \odot \mathrm{g}(\mathrm{t}) \odot 1\right) \overline{\mathrm{G}}(\mathrm{t})
$$

Taking LT of relations (8) solving for $\mathrm{B}_{0}^{*}(\mathrm{t})$. The time for which server is busy is given by

$$
\mathrm{B}(\infty)=\lim _{\mathrm{S} \rightarrow 0} \mathrm{~s} \mathrm{~B}_{0}^{\mathrm{R}^{*}}(\mathrm{~s})=\frac{\mathrm{N}_{2}}{\mathrm{D}_{1}}=\frac{\mathrm{w}_{2}^{*}}{\mu_{0} \mathrm{p}_{20}+\mu_{1}^{\prime} \mathrm{p}_{20}+\mu_{2}^{\prime}}
$$

\subsection{Expected Number of Visits by the Server}

Let $\mathrm{N}_{\mathrm{i}}(\mathrm{t})$ be the expected number of visits by the server for repair in $(0, \mathrm{t}]$ given that the system entered the regenerative state iat $\mathrm{t}=0$. The recursive relations for $\mathrm{N}_{\mathrm{i}}(\mathrm{t})$ are given as: 


$$
\begin{aligned}
& \mathrm{N}_{0}(\mathrm{t})=\mathrm{Q}_{01}{ }^{\circledR} \mathrm{N}_{0}(\mathrm{t}) \\
& \mathrm{N}_{1}(\mathrm{t})=\left[\mathrm{Q}_{12}(\mathrm{t})+\mathrm{Q}_{12 \cdot 34}(\mathrm{t})+\mathrm{Q}_{12 \cdot 37(4,6)^{\mathrm{n}}}(\mathrm{t})+\mathrm{Q}_{12 \cdot 374}(\mathrm{t})+\mathrm{Q}_{12 \cdot 3(4,6)^{\mathrm{n}}}(\mathrm{t})\right] \circledast\left[1+\mathrm{N}_{2}(\mathrm{t})\right] \\
& N_{2}(t)=Q_{20}(t) \circledR N_{0}(t)+\left[Q_{22 \cdot 5}(t)+Q_{22 \cdot 5(6,4)^{n}}(t)\right] ® N_{2}(t)
\end{aligned}
$$

Taking LT of relations (9) and solving for $\mathrm{N}_{0}^{* *}(\mathrm{~s})$. The expected no of visits bythe server can be obtained as:

$$
\mathrm{N}_{0}(\infty)=\lim _{\mathrm{s} \rightarrow 0} s \mathrm{~N}_{0}^{* *}(\mathrm{~s})=\frac{\mathrm{N}_{3}}{\mathrm{D}_{1}}=\frac{1-\mathrm{p}_{22 \cdot 5}-\mathrm{p}_{22 \cdot 5(6,4)^{\mathrm{n}}}}{\mu_{0} \mathrm{p}_{20}+\mu_{1}^{\prime} \mathrm{p}_{20}+\mu_{2}^{\prime}}
$$

\section{PROFIT ANALYSIS}

Profit incurred to the system model in steady state is given byP $=\mathrm{K}_{1} \mathrm{~A}-\mathrm{K}_{2} \mathrm{~B}-\mathrm{K}_{3} \mathrm{Nwhere}$, $\mathrm{K}_{1}=$ Revenue per unit up time of the system, $\mathrm{K}_{2}=$ Cost per unit time for which server is busy and $\mathrm{K}_{3}=$ Cost per visit by the server.

\section{CONCLUSIONS}

The reliability measures of the system model have been evaluated by assuming arrival and repair times as exponentially distributed $\left(\alpha \mathrm{e}^{-\alpha \mathrm{t}}\right.$ and $\left.\beta \mathrm{e}^{-\beta \mathrm{t}}\right)$. The graphs plotted for these measures indicate that the reliability measuresgo on decreasing with the increase in failure rate. However, there is a sharp decline in MTSF as compared to that ofavailability and profit. On the other hand the reliability measures will have an upward trend with the increase of arrival rate of the server and repair rate.

Hence it is concluded that better repair ratewith less arrival time increase the MTSF and profit of the system.

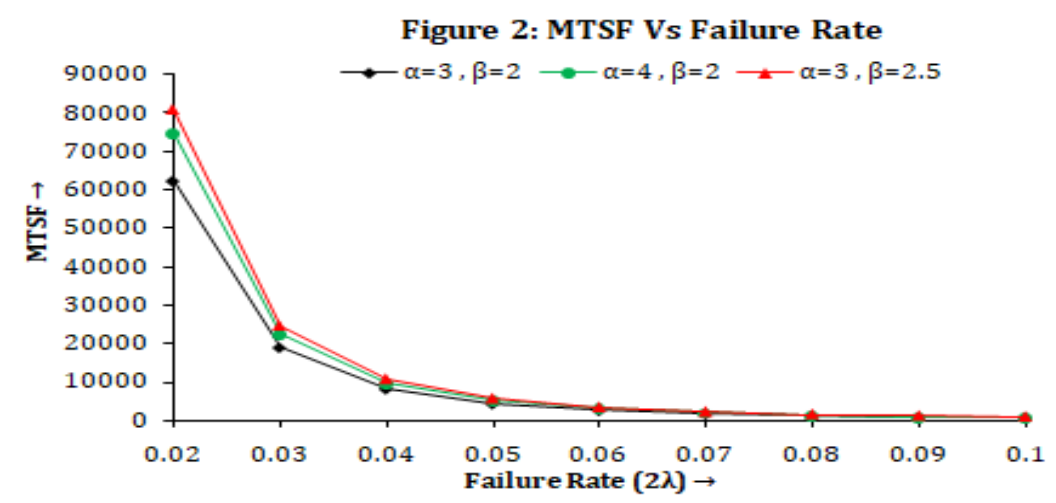

Figure 2: MTSF Vs Failure Rate.

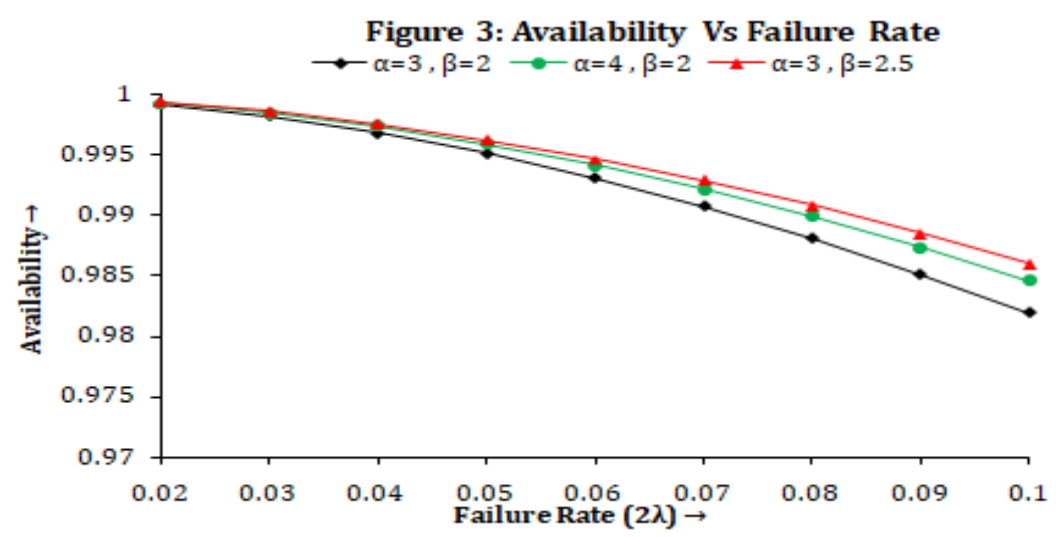

Figure 3: Availability Vs Failure Rate. 


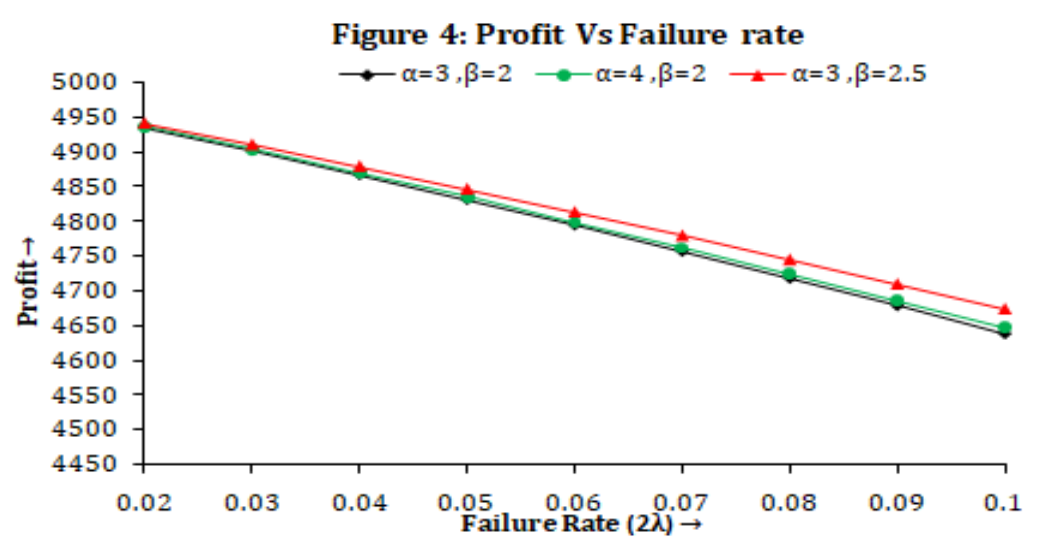

Figure 4: Profit Vs Failure Rate.

\section{REFERENCES}

1. Chopra, Garima and Ram, Mange (2017): Stochastic analysis of two non-identical unit parallel system incorporating waiting time, International journal of quality \& Reliability Management, Vol. 34 No. 6, pp. 817832

2. Garg V, Kadian M.S. (2016): Profit analysis of a two-unit cold standby system subject to preventive maintenance, International Journal of Statistics and Reliability Engineering in Vol.3 (I), pp. 2939.

3. Kumar, Ashok, Pawar, Dheeraj and Malik S.C. (2018): Economic analysis of a warm standby system with single server, International Journal of Mathematics and Statistics Invention, Volume 6, Issue 5, pp. 0106.

4. Joyce, V. Jemmy, and K. REBBECA JEBASEELI EDNA. "Designing and Selection of Reliability Based Sampling Plans." International Journal of Mechanical and Production Engineering Research and Development (IJMPERD) 8.4 (2018): 343348 .

5. Malik, S.C. and Bhardwaj, R.K. (2007): Reliability and cost benefit analysis of 2-out-of-3 redundant system with general distribution of repair and waiting time, International Journal for Business and IT (DTR), Vol. 4, Iss. 1, pp. 28-35

6. Malik, S.C. andGitanjali (2012): Analysis of a parallel system with maximum repair time and single server who appears and disappears randomly, International Journal of Mathematical Archive, 2012, 3 (11),pp. 47004707.

7. Yekini, SalawuEnesi, et al. "Investigation of production output for improvement." International Journal of Mechanical and Production Engineering Research and Development 8.1 (2018): 915922.

8. Malik, S.C. and Pawar, Dheeraj (2010): Reliability and economic measures of a system with inspection for on-line repair and no repair activity in abnormal weather, Bulletin of Pure and Applied Sciences, Vol. 29 E, Issue 2, pp. 355-368.

9. Murari, K. and Goyal, V. (1984): Comparison of two-unit cold standby reliability models with three types of repair facilities, Journal of Microelectronics and Reliability, Vol. 24(1), pp. 35-49

10. Kiran, R., and SdSivakumar. "A scale to measure the attitude of farmers towards vegetable supply chain management." International Journal of Educational Science and Research (IJESR) 7 (2017): 8188.

11. Pawar, D. and Malik, S.C. and Kumar, Jitender(2010): Analysis of a system working under different weather conditions with on-line repair and random appearance of the server at partial failure stage,International Journal of Statistics and Systems, Vol. 5, No. 4, pp. 485-496.

12. Sivanesan, G. "A Study of Talent Management Strategies in Information Technology Industry at Bangalore City." International Journal of Business Management \& Research (IJBMR) 4.5 (2014): 2130. 
13. Pawar, D. and Malik, S.C. (2011): Performance measures of a single-unit system subject to different failure modes with operation in abnormal weather, International Journal of Engineering Science and Technology, Vol. 3, No. 5, pp. 4084-4089.

14. Singh, S.K.(1989): Profit evaluation of a two-unit cold standby system with random appearance and disappearance time of service facility. Microelectron. Reliab. Vol. 29, pp. $705-709$. 

